\title{
Factors Influencing Early Health Facility Contact and Low Default Rate among New Sputum Smear Positive Tuberculosis Patients, India
}

\author{
Ashok Kumar Bhardwaj, ${ }^{1}$ Surender Kashyap, ${ }^{2}$ Pradeep Bansal, ${ }^{1}$ Dinesh Kumar, \\ Sunil Kumar Raina, ${ }^{1}$ Vishav Chander, ${ }^{1}$ and Sushant Sharma ${ }^{1}$ \\ ${ }^{1}$ Department of Community Medicine, Dr. Rajendra Prasad Government Medical College, \\ Kangra, Himachal Pradesh 176001, India \\ ${ }^{2}$ Kalpana Chawla Government Medical College, Karnal, Haryana, India
}

Correspondence should be addressed to Dinesh Kumar; dinesh9809@gmail.com

Received 13 November 2013; Revised 3 February 2014; Accepted 4 February 2014; Published 6 March 2014

Academic Editor: Hisako Matsumoto

Copyright (C) 2014 Ashok Kumar Bhardwaj et al. This is an open access article distributed under the Creative Commons Attribution License, which permits unrestricted use, distribution, and reproduction in any medium, provided the original work is properly cited.

\begin{abstract}
Early case identification and prompt treatment of new sputum smear positive case are important to reduce the spread of tuberculosis (TB). Present study was planned to study the associated factors for duration to contact the health facility since appearance of symptoms and treatment default. Methodology. It was prospective cohort study of TB patients already registered for treatment in randomly selected TB units (TUs) in Himachal Pradesh, India. Relative risk (RR) was calculated as risk estimate to find out the explanatory variables for early contact and default. Results. Total 1607 patients were recruited and $25(1.5 \%)$ defaulted treatment. Patients from nuclear family (aRR: 1.37; 1.09-1.73), ashamed of TB (aRR: 1.32; 1.03-1.70), wishing to disclose disease status (aRR: $1.79 ; 1.43-2.24$ ), but aware of curable nature (aRR: 1.67; 1.17-2.39) and preventable (aRR: 1.35; 1.07-1.70) nature of disease, contacted health facility early since appearance of symptoms. Conclusion. Better awareness and less misconceptions about disease influences the early contact of health facility and low default rate in North India.
\end{abstract}

\section{Introduction}

One-third of the world population is infected with Mycobacterium tuberculosis causing disease in about 10 million individuals and resulting in 1.3 million deaths per year. Asia and Africa regions together share $85.0 \%$ of the global disease burden [1]. India notified total 1.3 million cases including 0.62 million sputum smear positive cases [2]. Evidence from India showed that tuberculosis (TB) contributes about 30\% of deaths due to communicable disease and 7\% of total deaths [2]. Based upon World Health Organization (WHO) recommendations, the Government of India implemented Directly Observed Treatment Short Course (DOTS) strategy under Revised National Tuberculosis Program (RNTCP) [2]. Since then, treatment success rate among sputum smear positive patients improved from $25 \%$ in the year 1985 to about $90 \%$ by the year 2011 [2] as compared to the global treatment success rate of $84 \%$ [1]. Early case detection and treatment is a public health principle for disease control. Under RNTCP, an awareness campaign for signs and symptoms of TB demands an early contact of health facility for diagnosis. Contact of patient to health facility for treatment compliance depended on the program and patient related factors [3-5]. A lot has been done for disease awareness under program; the community behavior becomes supportive toward patient. However, evidence also showed that still stigma associated with signs and symptoms of TB, availability of diagnostic, and treatment services under RNTCP. Patients tend to hesitate and choose not to disclose their disease status to their family/friends out of fear of being socially marginalized [36]. The nature and degree of influence of such factors on health facility contact and so compliance for DOTS have not been reported as often. Therefore, the present study was planned to understand the role of factors in contacting 
a health facility since the appearance of symptoms and treatment default among patients on DOTS under RNTCP, Himachal Pradesh, India.

\section{Methodology}

It was a prospective cohort study of two years' (2008-09) duration conducted at randomly selected tuberculosis units (TUs) in the state of Himachal Pradesh, India. As per the census of 2011, the state has population of about 7 million spread over $55,670 \mathrm{~km}^{2}$ area residing in 12 districts. Sample size of 1537 was calculated with default rate of $4.0 \%$ (based upon the selected TUs for study) at 5\% significance level and $80 \%$ of study power. Sample size was revised to 1691 with $10 \%$ nonresponse rate. Interview was done to collect the data by the trained project staff using pretested and structured questionnaire.

Patients were getting DOTS for the period of six months from the DOTS providers as per the RNTCP. All new smear positive (NSP) TB cases with more than 15 years of age already on DOTS from selected TUs of study area were recruited. Once recruited every patient was contacted three times: first, as soon as they started with DOTS, second, at the end of intensive phase of DOTS, and, third, one week before completion of DOTS (i.e., at the time of administration of last dose of DOTS). A patient was considered to be a defaulter if he/she interrupted the treatment for two consecutive months or more. All the defaulted patients were contacted to assess the reason for default and were motivated to continue the DOTS. Based on review, studies differentially had used the definition for "delay in health facility contact" and no such clear definition is being used under RNTCP. Therefore, a cutoff of 30 days for deciding the early facility contact was considered after calculation of central tendency (median) of duration (days) of health facility contact since the appearance of symptoms.

RNTCP is providing DOTS to the patients through total 41 TUs in the state. Total 20 TUs were selected based upon population proportion to size (PPS) using the cluster sampling technique. Retrospective information was collected from patients already on DOTS who were interviewed about their place of residence, type of family, socioeconomic class, appearance of symptoms, time of contact to a health facility, substance abuse, disease knowledge, and misconceptions. Information about the health system related factors like distance of health facility from the place of residence and waiting time at centre and exact treatment duration explained by the DOTS provider was also asked from the patient. Prospective information in next two subsequent visits was also collected for sputum conversion, drug side effects, and family and society response towards the patient. If defaulted patient did not respond to the DOTS then patient was contacted prospectively at the place of residence by the project staff to assess the reasons for default. Data was collected on structured questionnaire and was translated into local language and back to English before the data collection. Before recruiting the patient an informed consent was taken in the first visit explaining that there would be further collection of information in the next two consecutive visits.
A prior ethical clearance from institutional ethics committee was also obtained.

Data was entered and analyzed using Epi Info software version 3.3.2 for Windows. Effect size in terms of relative risk (RR) with 95\% confidence interval (CI) was also calculated. The continuous variables were recoded into categorical variable and the reference category was selected and was compared with the rest of categories. Multivariate analysis using bimodal logistic regression was carried out for control of confounding and adjusted effect size (aRR) was computed. Multivariate analysis was not carried out for defaulters and nondefaulter patients due to less (25) number of treatment defaulters.

\section{Results}

Total 1607 patients were enrolled from all the randomly selected TUs and followed up in the study. Patients were largely from rural $(80.0 \%)$ area, male $(67.9 \%)$, and of $15-$ 44 years $(62.3 \%)$ of age group. Almost half of the patients had joint family of middle socioeconomic class (65.5\%) with more than three members $(86.5 \%)$ in the family. Majority reported alcohol (56.9\%) consumption and smoking (54.4\%) at the time of interview. It was observed that only 25 (1.5\%) patients defaulted (1.5\%) DOTS. Comparatively, the number of defaulted patients was small to look for statistically significant difference, but most of patients (76.0\%) thought that $\mathrm{TB}$ and its treatment affect their work performance, $56.0 \%$ hid their disease status from others, and $52.0 \%$ did not disclose their disease status to their family members. Despite this, $96.0 \%$ of defaulted patients were aware of the curable nature of disease and $84.0 \%$ knew about the duration of available treatment (data not shown).

Since appearance of symptoms, patients were put on DOTS after median (mean: 49 days; mode: 33 days) duration of 33 days. Treatment was started after more than 30 days among $55.6 \%$ of patients. Once patient contacted the health facility, treatment was started within 2.4 day. Most of the patients (62.1\%) first contacted government health facility for care. Almost all (95.5\%) patients were on category I treatment of DOTS.

Significantly early (within 30 day) contact to health facility was observed among patients of upper socioeconomic status (RR: 1.80; CI: 1.72-1.88), nuclear family (RR: 1.27; CI: $1.04-1.55)$ with family size of $3-5$ (RR: 1.22 ; CI: $1.00-$ 1.49 ), and of rural area (RR: 1.55; CI: 1.20-2.00). Early contact was observed less among patients of urban area (RR: 0.64; CI: 0.48-0.83) (Table 1). When analyzed for patient related factors, it was found that significantly more patients contacted health facility early, who felt ashamed about their disease status (RR: 1.41; CI: 1.15-1.74), but, ready to disclose their disease status (RR: 1.63; CI: 1.33-1.98), thought that treatment would be costly (RR: 2.08; CI: 1.40-3.09), and they knew disease is curable (RR: 1.96; CI: 2.43-2.69) and could be prevented by vaccine (RR: 1.29; CI: 1.05-1.59). Significantly fewer patients contacted early who wished to hide the disease from others (RR; 0.80; CI: 0.65-0.97). It was also observed that the exact treatment duration was explained by DOTS 
TABLE 1: Demographic profile among TB patients with default and delay treatment, Himachal Pradesh, India, 2008-09.

\begin{tabular}{|c|c|c|c|c|}
\hline Characteristics & $\begin{array}{c}\text { Delay (<30 day) } \\
(713) \\
N(\%) \\
\end{array}$ & $\begin{array}{c}\text { Delay (>30 day) } \\
(894) \\
N(\%) \\
\end{array}$ & $\begin{array}{l}\text { Risk estimate } \\
\text { (Unadjusted) } \\
\text { RR (95\% CI) }\end{array}$ & $\begin{array}{l}\text { Risk estimate } \\
\text { (Adjusted) } \\
\text { aRR (95\% CI) }\end{array}$ \\
\hline \multicolumn{5}{|l|}{ Age group (years) } \\
\hline $15-24$ & $191(27.2)$ & $208(23.5)$ & $1.23(0.98-1.50)$ & Ref \\
\hline $25-34$ & $156(22.2)$ & $172(19.4)$ & $1.17(0.92-1.48)$ & $1.05(0.75-1.47)$ \\
\hline $35-44$ & $111(15.8)$ & $152(17.2)$ & $0.90(0.68-1.17)$ & $1.39(0.93-2.07)$ \\
\hline $45-54$ & $92(13.1)$ & $137(15.5)$ & $0.81(0.61-1.08)$ & $1.46(0.97-2.21)$ \\
\hline 55 and above & $153(21.8)$ & $217(24.5)$ & $0.85(0.67-1.07)$ & $1.26(0.87-1.82)$ \\
\hline \multicolumn{5}{|l|}{ Sex } \\
\hline Male & $501(70.3)$ & $590(66.0)$ & $1.21(0.98-1.50)$ & $1.55(1.18-2.04)$ \\
\hline \multicolumn{5}{|l|}{ Status } \\
\hline Married & $479(67.2)$ & $622(69.6)$ & $0.89(0.72-1.10)$ & $1.05(0.78-1.40)$ \\
\hline \multicolumn{5}{|c|}{ Socioeconomic status } \\
\hline Upper & $0(0.0)$ & $07(00.8)$ & $1.80(1.72-1.88)^{*}$ & - \\
\hline Upper middle & $167(23.4)$ & $174(19.5)$ & $1.26(0.60-1.99)$ & $0.47(0.44-1.54)$ \\
\hline Lower middle & $310(43.5)$ & $402(45.0)$ & $0.91(0.77-1.14)$ & $0.54(0.16-1.75)$ \\
\hline Upper lower & $231(32.4)$ & $302(33.8)$ & $0.93(0.76-1.15)$ & $0.55(0.17-1.76)$ \\
\hline Lower & $5(0.7)$ & $009(01.0)$ & $0.69(0.23-2.08)$ & Ref \\
\hline \multicolumn{5}{|l|}{ Religion } \\
\hline Hindus & $686(96.2)$ & $855(95.6)$ & $1.15(0.70-1.91)$ & $1.06(0.62-1.82)$ \\
\hline \multicolumn{5}{|l|}{ Family } \\
\hline Nuclear & $361(50.6)$ & $399(44.6)$ & $1.27(1.04-1.55)^{*}$ & $1.37(1.09-1.73)^{*}$ \\
\hline \multicolumn{5}{|l|}{ Family size } \\
\hline$<3$ & $75(10.5)$ & $141(15.8)$ & $0.62(0.46-0.84)^{*}$ & Ref \\
\hline$>3$ & $333(46.7)$ & $372(41.6)$ & $1.22(1.00-1.49)^{*}$ & $0.68(0.48-0.97)^{*}$ \\
\hline \multicolumn{5}{|l|}{ Place of residence } \\
\hline Rural & $597(83.8)$ & $688(77.0)$ & $1.55(1.20-2.00)^{*}$ & Ref \\
\hline Urban & $98(13.8)$ & $180(20.1)$ & $0.63(0.48-0.82)^{*}$ & $0.69(0.51-0.93)^{*}$ \\
\hline \multicolumn{5}{|l|}{ Alcohol } \\
\hline Yes & $416(58.3)$ & $499(55.8)$ & $1.10(0.90-1.35)$ & $1.21(0.93-1.59)$ \\
\hline \multicolumn{5}{|l|}{ Smoking } \\
\hline Yes & $72(10.1)$ & $094(10.5)$ & $0.95(0.69-1.32)$ & $0.91(0.63-1.30)$ \\
\hline
\end{tabular}

*Statistically significant.

provider (RR: 1.96; CI: $1.26-3.04)$ to patients who contacted health facility early (Table 2 ).

Multivariate analysis showed that significantly more patients contacted health facility early and they were males (aRR: 1.55; CI: 1.18-2.04), from nuclear family (aRR: 1.37; CI: 1.09-1.73) (Table 1), and ashamed of their disease status (aRR: 1.32; CI: 1.03-1.70), wished to disclose disease status (aRR: 1.79; CI: 1.43-2.24), thought treatment would be costly (aRR: 2.45; CI: 1.59-3.78) but were aware of curable nature (aRR: 1.67; CI: 1.17-2.39) of disease and aware of available vaccine (aRR: 1.35; CI: 1.07-1.70) for prevention and health facility (aRR: 1.72; CI: 1.08-2.74) which was more than 60 minutes away from place of residence (Table 2). Fewer patients contacted the health facility early and they were from urban area (aRR: 0.69; CI: 0.51-0.93) (Table 1), with family size of 3-5 (aRR: 0.68; CI: 0.48-0.97), 6-7 (aRR: 0.60; CI: 0.41-0.89), wished to hide status from others (aOR: 0.69; CI: $0.51-0.93$ ), and thought that disease would affect daily work
(aRR: 0.73; CI: 0.56-0.97) performance. It was observed that the correct treatment duration was explained by the DOTS provider (aRR: 1.88; CI: 1.12-3.15) to patients who contacted health facility early (Table 2).

\section{Discussion}

With about 2 million deaths a year in the world and 7.0\% of total deaths in India, $\mathrm{TB}$ is a prevalent public health problem $[1,2,7]$. In the last 50 years, reduction in disease burden in India had been observed as national TB control efforts were expanded to the entire county [7, 8]. Early diagnosis and treatment of the case to break the chain of transmission were vital for disease control. Usually patients did not report to health facility early due to perceived mild nature of symptoms, bad staff behavior, and patient dissatisfaction $[9,10]$. Societal issues like expected problems related to social status, marriage, and adverse community 
TABLE 2: Disease awareness among TB patients with default and delay treatment, Himachal Pradesh, India, 2008-09.

\begin{tabular}{|c|c|c|c|c|}
\hline Characteristics & $\begin{array}{c}\text { Delay (<30 day) } \\
(713) \\
N(\%)\end{array}$ & $\begin{array}{c}\text { Delay (>30 day) } \\
(894) \\
N(\%)\end{array}$ & $\begin{array}{l}\text { Risk estimate } \\
\text { (Unadjusted) } \\
\text { RR }(95 \% \mathrm{CI})\end{array}$ & $\begin{array}{l}\text { Risk estimate } \\
\text { (Adjusted) } \\
\text { aRR (95\% CI) }\end{array}$ \\
\hline \multicolumn{5}{|l|}{ Stigma } \\
\hline Ashamed & $271(38.0)$ & $270(30.2)$ & $1.41(1.15-1.74)^{*}$ & $1.32(1.03-1.70)^{*}$ \\
\hline Hide from others & $402(56.4)$ & $552(61.7)$ & $0.80(0.65-0.97)^{*}$ & $0.70(0.55-0.88)^{*}$ \\
\hline Disclose to others & $384(53.9)$ & $373(41.7)$ & $1.63(1.33-1.98)^{*}$ & $1.79(1.43-2.24)^{*}$ \\
\hline Hereditary & $300(42.1)$ & $362(40.5)$ & $1.07(0.87-1.31)$ & $1.03(0.81-1.31)$ \\
\hline Prefer to be isolated & $181(25.4)$ & $212(23.7)$ & $1.09(0.87-1.37)$ & $1.08(0.83-1.39)$ \\
\hline Costly treatment & $068(09.5)$ & $043(04.8)$ & $2.08(1.40-3.09)^{*}$ & $2.45(1.59-3.78)^{*}$ \\
\hline \multicolumn{5}{|l|}{ Effect } \\
\hline Work & $502(70.4)$ & $661(73.9)$ & $0.83(0.67-1.04)$ & $0.73(0.56-0.97)$ \\
\hline Marriage & $218(30.6)$ & $270(30.2)$ & $1.01(0.82-1.26)$ & $0.99(0.77-1.28)$ \\
\hline Responsibility & $385(54.0)$ & $466(52.1)$ & $1.07(0.88-1.31)$ & $0.98(0.76-1.25)$ \\
\hline Female infertility & $145(20.3)$ & $149(16.7)$ & $1.27(0.99-1.64)$ & $1.22(0.93-1.61)$ \\
\hline \multicolumn{5}{|l|}{ Knowledge } \\
\hline DOTS duration & $713(90.9)$ & $894(89.0)$ & $1.22(0.88-1.70)$ & $0.86(0.56-1.31)$ \\
\hline Curable & $648(90.9)$ & $796(89.0)$ & $1.96(2.43-2.69)^{*}$ & $1.67(1.17-2.39)^{*}$ \\
\hline Contagious & $376(52.7)$ & $477(53.4)$ & $0.98(0.81-1.20)$ & $1.05(0.83-1.32)$ \\
\hline Vaccine & $267(37.4)$ & $282(31.5)$ & $1.29(1.05-1.59)^{*}$ & $1.35(1.07-1.70)^{*}$ \\
\hline \multicolumn{5}{|l|}{ Advertisement } \\
\hline Yes & $642(90.0)$ & $781(87.4)$ & $1.30(0.95-1.79)$ & $1.18(0.83-1.68)$ \\
\hline \multicolumn{5}{|c|}{ Time to DOTS centre (minutes) } \\
\hline$<30$ & $470(65.9)$ & $587(65.7)$ & $0.97(0.79-1.20)$ & Ref \\
\hline$>30$ & $205(28.8)$ & $264(29.5)$ & $1.02(0.83-1.26)$ & $1.72(1.08-2.74)^{*}$ \\
\hline \multicolumn{5}{|c|}{ Waiting time at DOTS center (minutes) } \\
\hline$<30$ & $538(75.5)$ & $687(76.8)$ & $0.93(0.74-1.17)$ & Ref \\
\hline$>30$ & $151(21.2)$ & $175(19.6)$ & $1.07(0.85-1.35)$ & $0.98(0.75-1.27)$ \\
\hline \multicolumn{5}{|l|}{ Provider explained } \\
\hline DOTS duration & $683(95.8)$ & $823(92.1)$ & $1.96(1.26-3.04)^{*}$ & $1.88(1.12-3.15)^{*}$ \\
\hline
\end{tabular}

${ }^{*}$ Statistically significant.

behavior were major reasons for stigmatizing behavior of patient $[11,12]$. These factors result in late case identification and result in disease transmission in the community. Present study showed that the patients who contacted health facility early were those who felt ashamed of the disease but ready to disclose disease status to others. Few patients contacted the health facility early because they wished to hide their disease status from others and thought that the disease would affect their daily work performance. Present study observed weak evidence for disease effect on work capacity, family relations, marriage, and female infertility (Table 2 ).

Prior disease knowledge and awareness influence the health care seeking behavior. It was observed that patients who were on treatment were aware of infectious nature of disease and its available treatment [13]. Present study also showed that patients who contacted health facility early were aware of the preventable and curable nature of disease. In present study, correct treatment duration was explained by the DOTS provider among patients who contacted the health facility early. Present study observed average duration of delay of 30 days which is low as compared to about 56 reported by other studies in an African country [14]. This difference amounts to perceived nature of symptoms and penetration of program in terms of availability and accessibility of management services in the country [3-6].

In India, treatment success rate approached $85.0 \%$ and met the set objective under RNTCP [15]. Poor treatment compliance could lead to high default rate and pose threat to multidrug resistant tuberculosis. However, present study had showed default rate of $1.5 \%$ similar to $1.1 \%$ as observed in North India [16]. Present study observed that defaulted patients still did not disclose their disease status to their family members and friends despite their correct knowledge about the duration of treatment and curable nature of disease. Smoking [7] and alcohol $[17,18]$ are known to increase the risk of mortality and high default rate among patients with substance abuse [12]. Present study observed insignificant but high prevalence of alcohol (76.0\%) and smoking (12.0\%). Against the reported (before the study was based upon routine health information system) default rate of $3.8 \%$ of 
selected TUs, present study observed low default which could be due to two prospective visits study design, in addition to the usual inbuilt patient monitoring under the program.

In the present study, disease awareness and complete information provided by the DOTS provider influenced early contact of health facility and low treatment default rate. High level of advertisement under RNTCP possibly had played a significant role in the study area. Low default rate could be attributed to study design itself as patient was approached by the study staff three times. It poses a limitation of study as it could not the controlled in study design, but it shows that additional visits to contact patient could reduce the treatment default rate. RNTCP has strengthened itself to achieve high case detection and cure rate. It will substantiate the successful efforts in the state to combat TB as one of the top ten leading killers.

\section{Conflict of Interests}

The authors declare that there is no conflict of interests regarding the publication of this paper.

\section{Acknowledgment}

The financial assistance was provided by the Central Tuberculosis Division, Ministry of Health and Family Welfare, Government of India.

\section{References}

[1] World health organization (WHO), Global Tuberculosis Control, World health organization, 2010.

[2] "People on health," Annual Report, Government of India, Ministry of Health and Family Welfare, New Delhi, India, 2010.

[3] K. Jaggarajamma, R. Ramachandran, N. Charles, V. Chandrasekaran, M. Muniyandi, and S. Ganapathy, "Psycho-social dysfunction: perceived and enacted stigma among tuberculosis patients registered under Revised National Tuberculosis Control Programme," The Indian Journal of Tuberculosis, vol. 55, no. 4, pp. 179-187, 2008.

[4] G. Sudha, C. Nirupa, M. Rajasakthivel et al., "Factors influencing the care-seeking behaviour of chest symptomatics: A community-based study involving rural and urban population in Tamil Nadu, South India," Tropical Medicine and International Health, vol. 8, no. 4, pp. 336-341, 2003.

[5] R. Rajeswari, V. Chandrasekaran, M. Suhadev, S. Sivasubramaniam, G. Sudha, and G. Renu, "Factors associated with patient and health system delays in the diagnosis of tuberculosis in South India," International Journal of Tuberculosis and Lung Disease, vol. 6, no. 9, pp. 789-795, 2002.

[6] V. K. Dhingra and S. Khan, "A sociological study on stigma among TB patients in Delhi," Indian Journal of Tuberculosis, vol. 57, no. 1, pp. 12-18, 2010.

[7] P. Jha, B. Jacob, V. Gajalakshmi et al., "RGI-CGHR Investigators. A nationally representative case-control study of smoking and death in India," The New England Journal of Medicine, vol. 358, no. 11, pp. 1137-1147, 2008.

[8] V. K. Dhingra, N. Aggarwal, S. Chandra, and R. P. Vashist, "Tuberculosis mortality trends in Delhi after implementation of
RNTCP,' Indian Journal of Tuberculosis, vol. 56, no. 2, pp. 77-81, 2009.

[9] N. Charles, B. Thomas, B. Watson, M. Raja Sakthivel, V. Chandrasekeran, and F. Wares, "Care seeking behavior of chest symptomatics: a community based study done in south india after the implementation of the RNTCP," PLoS ONE, vol. 5, no. 9, Article ID e12379, pp. 1-6, 2010.

[10] R. Dandona, L. Dandona, A. Mishra, S. Dhingra, K. Venkatagopalakrishna, and L. S. Chauhan, "Utilization of and barriers to public sector tuberculosis services in India," National Medical Journal of India, vol. 17, no. 6, pp. 292-299, 2004.

[11] V. K. Dhingra and S. Khan, "A sociological study on stigma among TB patients in Delhi," Indian Journal of Tuberculosis, vol. 57, no. 1, pp. 12-18, 2010.

[12] S. Atre, A. Kudale, S. Morankar, D. Gosoniu, and M. G. Weiss, "Gender and community views of stigma and tuberculosis in rural Maharashtra, India," Global Public Health, vol. 6, no. 1, pp. 56-71, 2011.

[13] N. Sharma, A. Nath, D. K. Taneja, and G. K. Ingle, "A qualitative evaluation of the information, education, and communication component of the tuberculosis control program in Delhi, India," Asia-Pacific Journal of Public Health, vol. 21, no. 3, pp. 321-332, 2009.

[14] M. Pai and D. Dowdy, "Tuberculosis: progress and challenges in product development and delivery," The Lancet Respiratory Medicine, vol. 2, no. 1, pp. 25-27, 2014.

[15] M. W. Borgdorff, K. Floyd, and J. F. Broekmans, "Interventions to reduce tuberculosis mortality and transmission in lowand middle-income countries," Bulletin of the World Health Organization, vol. 80, no. 3, pp. 217-227, 2002.

[16] G. Kaur, N. K. Goel, D. Kumar, A. K. Janmeja, H. M. Swami, and M. Kalia, "Treatment outcomes of patients placed on treatment under directly observed therapy short-course (dots)," Lung India, vol. 25, no. 2, pp. 75-77, 2008.

[17] V. Gajalakshmi and R. Peto, "Smoking, drinking and incident tuberculosis in rural India: population-based case-control study," International Journal of Epidemiology, vol. 38, no. 4, pp. 1018-1025, 2009.

[18] V. G. Rao, P. G. Gopi, J. Bhat, R. Yadav, N. Selvakumar, and D. F. Wares, "Selected risk factors associated with pulmonary tuberculosis among Saharia tribe of Madhya Pradesh, central India," European Journal of Public Health, vol. 22, no. 2, pp. 271$273,2012$. 


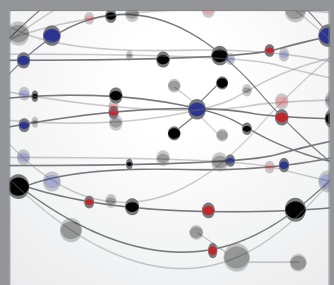

The Scientific World Journal
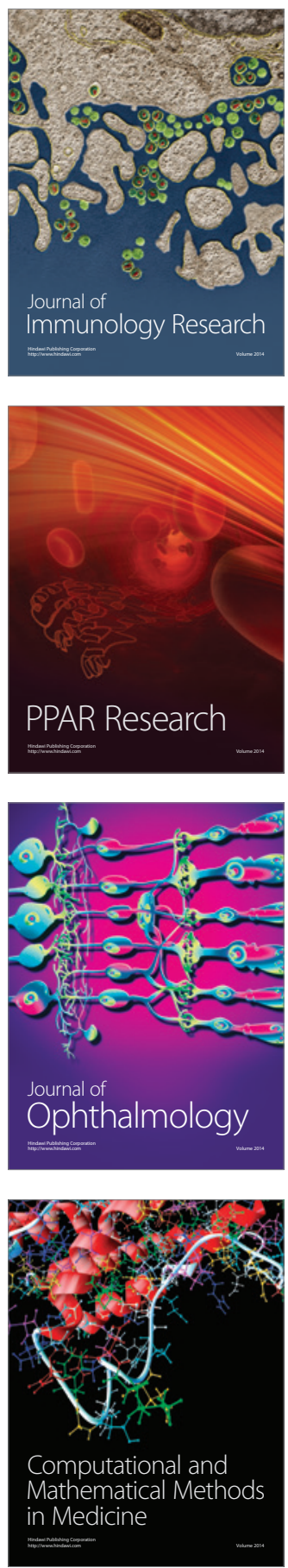

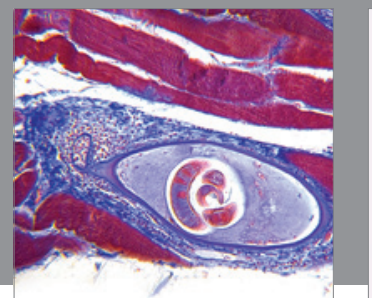

Gastroenterology

Research and Practice
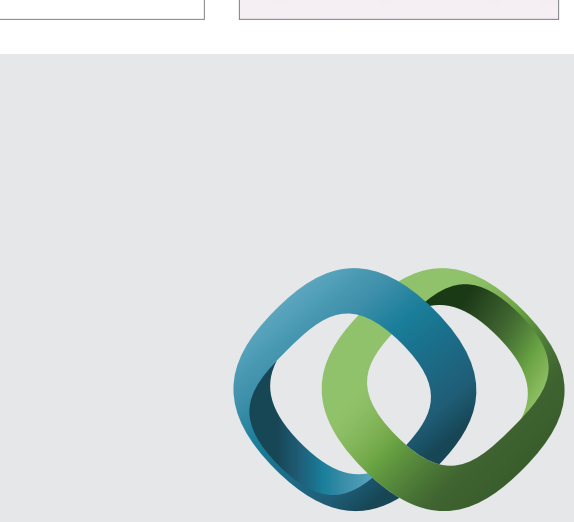

\section{Hindawi}

Submit your manuscripts at

http://www.hindawi.com
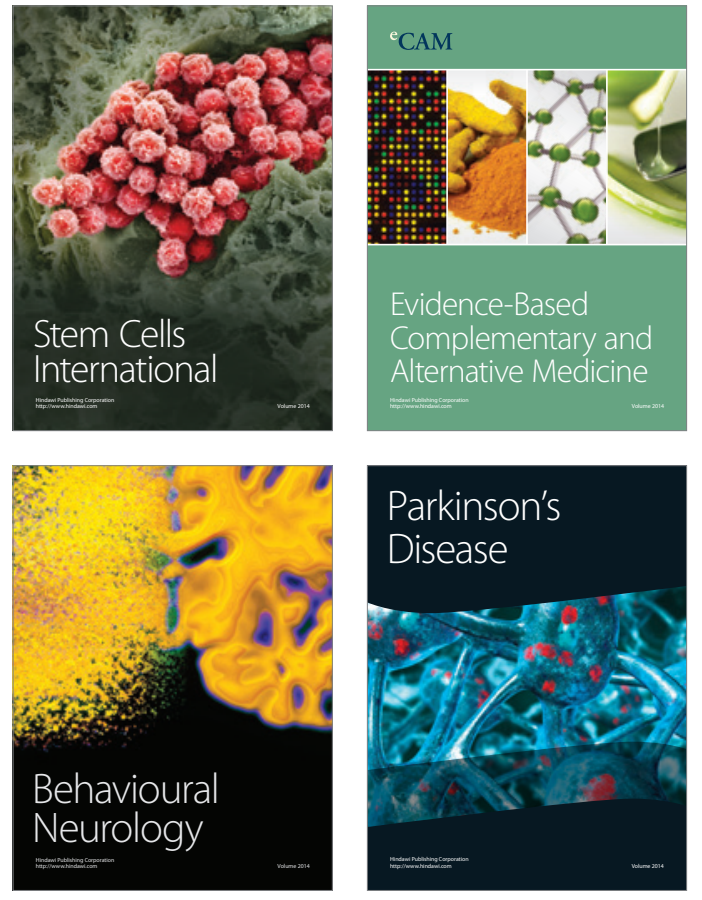
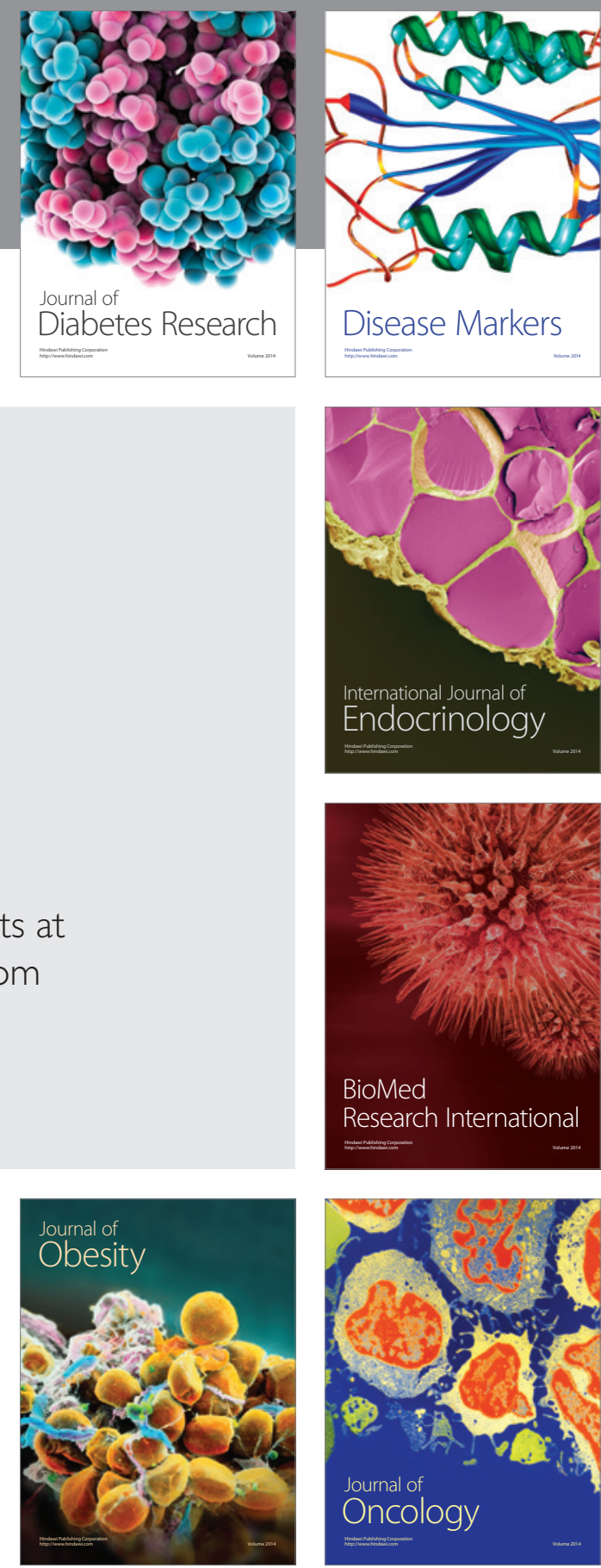

Disease Markers
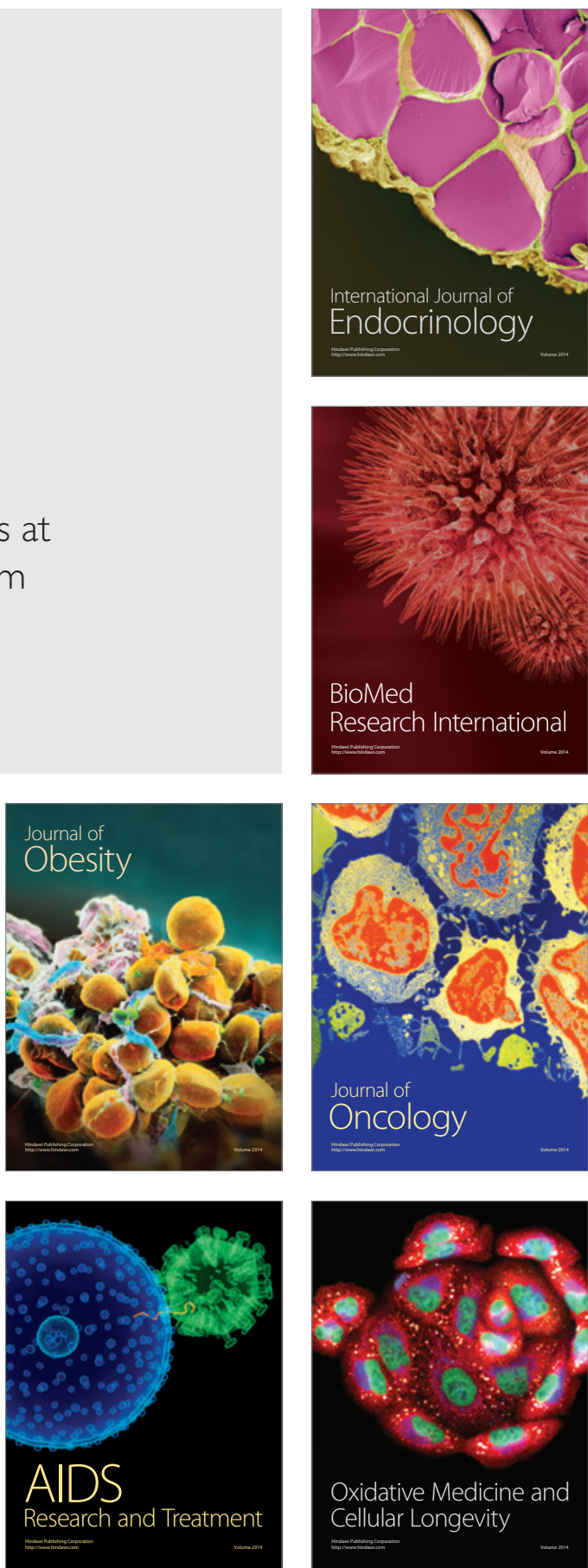